\title{
Teoría social sobre el origen de la nación: puntos de encuentro entre los paradigmas perennialista y modernista. Etnosimbolismo y otras vías eclécticas: la hipótesis de la continuidad-intensificación ${ }^{1}$
}

\author{
Social theory on the origins of the nation: meeting points between the perennialist and \\ modernist paradigms. Ethnosimbolism and other eclectic routes: the hypothesis of the \\ continuity-intensification
}

Lluís Català Oltra (Universitat d’Alacant, España)

Cita bibliográfica: Català Oltra, L. (2022). Teoría social sobre el origen de la nación: puntos de encuentro entre los paradigmas perennialista y modernista. Etnosimbolismo y otras vías eclécticas: la hipótesis de la 'continuidad-intensificación'. Disjuntiva, 3(1), 19-32. https://doi.org/10.14198/DISJUNTIVA2022.3.1.2

\section{Resumen}

El debate teórico sobre la nación y el nacionalismo se ha centrado demasiado a menudo en fijar fronteras temporales y localizar geográficamenteel fenómeno.Esedebate(quizá estéril)sobreelorigen temporal y espacial de la nación y el nacionalismo ha enfrentado en las últimas décadas fundamentalmente a dos paradigmas, (neo)perennialismo y modernismo. Como es conocido, la teoría modernista fija en el final del s. XVIII y principios del XIX el inicio de la "era de la nación y los nacionalismos", cuando la industrialización está fortaleciendo el papel de la burguesía y ésta comienza a apoyar reformas de carácter civil y político que modificarán los principios de soberanía. Por el contrario, los neoperennialistas, sobre todo apoyados en la revisión histórica de Hastings, se remontan a una época premoderna para datar el inicio de la nación y suelen recurrir al modelo inglés de formación del Estado y la nación (frente al modelo francés, postulado por gran parte de los modernistas). A pesar de los planteamientos antagónicos de ambos paradigmas, en este trabajo se destacarán los puntos de encuentro, para dar lugar a una visión ecléctica de los orígenes del fenómeno, que conectará en cierto modo con el etnosimbolismo y otras propuestas eclécticas.

\section{Palabras claves}

Nación; nacionalismos; modernismo; perennialismo; perspectiva histórica.

\begin{abstract}
The theoretical debate about the nation and nationalism has too often focused on fixing temporary borders and locating geographically the phenomenon. In the last decades, this (perhaps sterile) debate about temporal and spatial origin of the nation and nationalism has especially faced two paradigms: (neo)perennialism and modernism. As is well known, the modernist theory set the start of the nation and nationalisms era between the end of the XVIII century and the beginning of the XIX century. This is the time when the industrialization was strengthening the role of the bourgeoisie and it began to support civil and political reforms that will modify the sovereignty principle. On the contrary, specially based on Hastings' historical revision, the neoperennialists go back to a premodern age to date the beginning of the nation and they use to turn to the English model of State and nation building (facing the French model, postulated by a large part of the modernists). Despite the antagonistic approaches of both paradigms, in this work we emphasize the common ground to give rise to an eclectic view of the phenomenon origins. In some way this is linked to the ethnosimbolism and other eclectic proposals.
\end{abstract}

\section{Key words}

Keywords: nation; nationalisms; modernism; perennialism; historical perspective.

1. Una versión inicial de este escrito fue presentado como ponencia en el IX Congreso Español de Sociología, que tuvo lugar en Barcelona en julio de 2007.

L. Català: https://orcid.org/0000-0001-9426-6640

Correo electrónico de correspondencia: lluis.catala@gcloud.ua.es 


\section{Introducción}

Uno de los debates más polémicos en la tarea de explicación del fenómeno nacional es el relativo al origen de la nación ${ }^{1}$, especialmente a partir de 1997 cuando, por parte de Adrian Hastings, se hace pública una de las críticas más sólidas a la "ortodoxia modernista" y, más en concreto, a uno de sus autores más destacados, Eric Hobsbawm. Curiosamente, las dos obras principales de este enfrentamiento, las que lo escenifican, surgen de las Conferencias Wiles ${ }^{2}$ (Queen's University Belfast) de 1985 (Eric Hobsbawm) y 1996 (Adrian Hastings), que dieron lugar a dos publicaciones clave en la teoría social del nacionalismo: Nations and nationalism since 1780 (Eric Hobsbawm, 1990; se maneja la edición española de 1992), y The construction of nationhood (Adrian Hastings, 1997; se maneja la edición española de 2000). Este escrito tendrá muy en cuenta estas dos obras (son las que más énfasis ponen en el debate sobre el origen desde una y otra perspectiva, la modernista y la perennialista), pero también se apoyará en el resto de la teoría social sobre el nacionalismo, puesto que en la mayoría de la literatura se ha hecho alguna alusión al origen de la nación o a fechas o épocas de nacimiento. Se sostendrá que el debate sobre el origen de la nación esconde en algunos casos posiciones forzadamente distanciadas y que es posible captar a este respecto un consenso en la teoría social sobre el nacionalismo o, cuando menos, una posición ecléctica de cierta validez, que no tenga en la variable tiempo un obstáculo que impida una correcta aproximación al fenómeno, sino más bien un aliado estratégico (aplicando un enfoque histórico, tomando la nación como un producto de la longue durée).

Serán de gran importancia los conceptos de nación y nacionalismo que manejen unas y otras posiciones, pero también habrá que tener en cuenta la relación entre ambos términos, porque de ella va a depender en algunos casos la determinación de una época concreta como punto de partida de la nación: si se considera que ambos conceptos discurren temporalmente en paralelo, es decir, si se asume que no hay naciones sin nacionalismo (o viceversa), será indispensable que se pueda detectar la presencia de un movimiento o ideología nacionalista para poder hablar con propiedad de la aparición de la nación (y eso, con el permiso del perennialismo, difícilmente sucede antes de la época moderna); si, por el contrario, desligamos temporalmente ambos conceptos, se abre la posibilidad de que la nación pueda haber surgido antes que el nacionalismo (y por tanto, antes de la modernidad). Una aproximación evolutiva, que entienda el fenómeno como una realidad histórica, nos llevará a entender que en determinados momentos la nación ha precedido al nacionalismo y en otros episodios históricos ha sucedido al contrario.

En el debate sobre el origen de la nación, se trataría de determinar si las naciones son perennes en la historia, si son algo primordial a la condición humana o son el producto de unas condiciones específicamente modernas (Guibernau \& Hutchinson, 2004: 4), toda vez que para los paradigmas consolidados en ciencias sociales (perennialismo, modernismo y etnosimbolismo) parece que está claro que las naciones son una construcción social ${ }^{3}$. Al inicio del estudio del nacionalismo, pudo dominar el primordialismo, porque la intervención de los científicos era limitada y, desde ámbitos político-filosóficos se impuso en cierta medida esa visión primordialista en que la nación era una variable naturalmente determinada, como puedan ser también el sexo o la edad: todo el mundo (desde siempre) tiene su nación. A partir de Kedourie, y más aún de Gellner y Hobsbawm, toma cuerpo, ya claramente en el ámbito académico, la tesis modernista, que se convierte rápidamente en el paradigma dominante, en lo que se ha llamado la "ortodoxia" dentro del estudio del nacionalismo. Aunque aparecidas con anterioridad, en los 80, y de manera más visible en los 90, otras aproximaciones ("evolutivas", como le gusta denominar a Llobera; perennialismo; etnosimbolismo) han cobrado fuerza. El (neo)perennialismo surge entre los historiadores medievalistas como crítica radical al modernismo; los etnosimbolistas se apoyan en parte en esa crítica, pero añaden otro tipo de matices (como se verá más adelante) y no descartan por completo las tesis modernistas. En paralelo, hay aproximaciones de tipo histórico, evolutivas si se quiere, a veces difícilmente clasificables, que son relativamente recientes, y que se enmarcarían dentro de la crítica al modernismo para profundizar en una visión ecléctica. Estas líneas de trabajo que buscan una conciliación de mínimos entre los distintos paradigmas van a ser el rumbo a seguir en este recorrido por el debate sobre el origen de naciones y nacionalismos.

1. Como ha afirmado alguno de los autores, "la cuestión clave de nuestro cisma radica en la fecha de comienzo" (Hastings, 2000: 21); también Smith mantiene que, "de los diferentes asuntos que han dividido a los expertos en el estudio del nacionalismo, ninguno ha sido tan crítico como el problema del origen de las naciones" (citado en Guibernau \& Hutchinson, 2004: 2); o en positivo, "los argumentos acerca de la antigüedad o modernidad de la nación han jugado un decisivo papel en la estructuración de las diferentes aproximaciones al tema del nacionalismo" (Routledge, 2003: 213).

2. Las Conferencias Wiles (Wiles Lectures) se llevan realizando desde 1954 en la Queen's University de Belfast y son promovidas por una fundación cuyo objetivo es impulsar el estudio de la historia de las civilizaciones y, en general, difundir la perspectiva histórica en ciencias sociales. Cada año se invita a un historiador a que realice una serie de conferencias monográficas. Además de Hobsbawm o Hastings, también han sido invitados otros autores que han tenido el nacionalismo como objeto de estudio (Michael Mann, Terence Ranger o J.A. Gallagher).

3. Ésta será una de las premisas básicas en este escrito y el motivo por el cual se obviará el primordialismo en el contraste entre paradigmas. 


\section{El origen de la nación desde el paradigma modernista}

Una de las muestras de la centralidad del debate sobre el origen en la teoría social y la historia sobre el nacionalismo es que los paradigmas (desde dentro o desde fuera) se definen en relación a su posición respecto a ese origen de naciones y nacionalismo. Evidentemente, los modernistas ven en el inicio (o primeras etapas) de la época moderna, el momento en que se forjan naciones y nacionalismo. En palabras de Kedourie, éste no es universal ni necesario, y de ello se deduce automáticamente que está restringido espacial y temporalmente, y que responde a condiciones concretas que lo han hecho posible y (entonces sí) necesario. Por tanto, el nacionalismo hunde sus raíces en una época concreta, la modernidad ${ }^{4}$ (Gellner, 1998: 23), y eso es algo que ha generado un importante consenso entre buena parte de los sociólogos e historiadores que han tenido como materia de estudio la nación.

En primer lugar, hay que prestar atención a cómo concretan temporalmente los teóricos más importantes del paradigma el origen moderno. En general, se trabaja con un intervalo de tiempo bastante amplio que podría abarcar de finales del siglo XVIII (como veremos, hay "excepciones modernas" que se remontan al siglo XVI) hasta la segunda mitad del XIX (también hay excepciones que alcanzan hasta el siglo XX). Son momentos de profundos cambios, algunos de los cuales tendrán bastante que ver con el surgimiento y consolidación de naciones y nacionalismo. Con esas fechasfrontera, los modernistas (o la mayoría de ellos) quieren significar que "hay una ruptura radical entre las unidades y sentimientos premodernos y las naciones y nacionalismo modernos" (Smith, 1986: 13); las continuidades entre lo que Hobsbawm llama "protonacionalismo" y el nacionalismo (moderno) "es muy posible que sean artificiales" (Hobsbawm, 1992: 85). En la Francia que surge de la Revolución, "la etnicidad u otros elementos de continuidad histórica eran ajenos a la 'nación' (...) Y la patrie a la que iba dirigida su lealtad era lo contrario de una unidad preexistente, existencial, y en vez de ello era una nación creada por la elección política de sus miembros, los cuales, al crearla, rompieron con sus anteriores lealtades, o al menos rebajaron su categoría" (Hobsbawm, 1992: 96).

Como ya se comentó en la introducción, también es importante determinar si estos autores y sus seguidores consideran que las naciones anteceden al nacionalismo o al revés; en definitiva, qué podemos fechar en primer lugar, si la comunidad humana (con todas las particularidades que correspondan) o el movimiento o doctrina que la ensalza. Smith considera que prácticamente todos los modernistas afirman que el nacionalismo contribuyó a la creación de la nación (Guibernau \& Hutchinson, 2004: 2). A este respecto, fue Hobsbawm quien más claramente afirmó que "a efectos de análisis, el nacionalismo antecede a las naciones. Las naciones no construyen Estados y nacionalismos, sino que ocurre al revés" (Hobsbawm, 1992: 18). Si la nación es una construcción, y aún más, una invención (Hobsbawm \& Ranger, 1988: 23-24), es necesario que haya alguien que previamente la construya o la invente, y ése es uno de los cometidos de los nacionalistas. La construcción de la nación ayudó a legitimar el poder del Estado, a conseguir la lealtad de los ciudadanos al Estado y a sus gobernantes (Hobsbawm, 1992: 92). Por ello, a partir de la Revolución francesa, los gobiernos ejercieron una "ingeniería ideológica consciente y deliberada" (Hobsbawm, 1992: 101) buscando la eficacia en el objetivo de la adhesión nacional de los ciudadanos. Esta posición, expresada a través del pensamiento de diferentes autores "modernistas", se podría considerar uno de los preceptos básicos de la corriente, a pesar de que muchos de ellos no profundicen en este aspecto.

A partir de estos planteamientos básicos, ¿cuáles serían los fundamentos de la teoría modernista sobre el origen de las naciones?, ¿por qué las naciones y el nacionalismo son un fenómeno moderno que tiene su aparición no antes de la segunda mitad del siglo XVIII en Europa Occidental u otras regiones de su influencia (América, especialmente)? Globalmente, a partir de las aproximaciones teóricas de estos autores, debemos entender que la nación es "un producto de desarrollos estrictamente modernos como el capitalismo, la burocracia, el utilitarismo secular" (Smith, 1986: 8) $\mathrm{u}$ otros de los elementos que se han barajado en este epígrafe. Una interpretación de conjunto de los planteamientos modernistas podría quedar resumida en una secuencia en la que inicialmente es central la consolidación del modo de

4. La modernidad debe ser entendida como el proceso por el cual se impone la $\underline{\text { razón }}$ como norma trascendental a la sociedad. La racionalidad supone, "en su vertiente material, el principio del 'desarrollo ilimitado de las fuerzas productivas', según el cual todo (...) es calculable, producible (fenómeno revolución industrial); y en su vertiente política, el principio de igualdad universal de los hombres' por encima de sus diferencias cualitativas (etnia, creencia, sangre...). Este principio de racionalidad es históricamente introducido por la burguesía en la medida en que responde a sus intereses económicos (universalización de la relación mercantil: liquidación de las relaciones feudales) y políticos (democracia: derecho igual contra privilegios); intereses que expresan precisamente las necesidades del modo de producción capitalista o ley del valor, es decir, la base o estructura definitoria del mundo burgués" (Arnau \& Nieto, 2002: 3). En este apartado se concretarán ambas vertientes (económica y política) y sus implicaciones para la formación de las naciones, dentro de la secuencia de argumentos de los modernistas. 
producción capitalista (Anderson, 1993: 63; Hobsbawm, 1992: 18; Woods \& Grant, 2000: 2), que llevará aparejados algunos efectos directos sobre la formación de las naciones, como el desarrollo de la imprenta de gran producción (Anderson, 1993: 70), el establecimiento de mercados más amplios, "nacionales" (Hobsbawm, 1992: 49; Anderson, 1993: 70), o la aparición de "comunidades de tipo horizontal-secular" (Anderson, 1993: 63) en parte debido a la necesidad de que determinados puestos de trabajo los lleve a cabo la persona más preparada (Gellner, 1998: 26-39). Casi en paralelo, aunque dependiente de la consolidación del nuevo modo de producción, el Estado debe sufrir importantes transformaciones: racionalidad y centralización burocrática con un marco territorial definido (Hobsbawm, 1992: 89), con lo cual la unidad nacional se iba asentando como realidad compartida; incorporación progresiva de ciudadanos a la tarea de gobierno y gestión, y "uso" del ciudadano por parte del Estado (Hobsbawm, 1992: 92) a través de un nuevo entramado de derechos y obligaciones que posibilitaría la lealtad nacional de las masas; e incorporación de un "programa político nacional" (Breuilly, 1990: 16), no sólo como impulso, recuperación, enaltecimiento y/o desarrollo de la nación, sino también como discurso cotidiano (banalizado, como diría Michael Billig, 1995) del poder político (presencia en la burocracia, en las comunicaciones de los cargos públicos, en el desarrollo de las políticas, en la educación...). Finalmente, el nuevo modo de producción y, ahora, su correspondiente nuevo modelo de Estado se combinan para posibilitar una "cultura pública distintiva" (Smith, 2003: 28), una cultura pública homogénea o "alta cultura" compartida por un amplio número de ciudadanos (Gellner, 1998: 30-39), que surge a partir de la alfabetización y la vernacularización de la lengua impresa; se adquiere la conciencia nacional, "una conciencia secular y humanística, basada en los principios de soberanía popular e igualdad (...) La cultura moderna es fundamentalmente nacionalista en el sentido de que en su esencia concentra una visión nacionalista y esa visión se proyecta en cada esfera de la actividad cultural/social” (Greenfeld, 2005: 327).

Para concluir con la exposición sobre el origen de la nación desde el paradigma modernista, es necesario hacer hincapié en otro aspecto fundamental de su pensamiento (común a gran parte de los autores), que pueden ser tomado como elemento teórico diferencial respecto a otros paradigmas, siempre manteniendo como eje de la discusión el origen de naciones y nacionalismo. Se trata de la definición del nacionalismo como "fenómeno de masas". Este argumento ha sido de relativa importancia para ahondar en la brecha temporal que separa las sociedades premodernas (y por tanto prenacionales) de las modernas (y por tanto profundamente nacionales). Umut Özkirimli, uno de los autores modernistas más beligerantes, mantiene que naciones y nacionalismo no pueden existir si no son un fenómeno de masas, y se pregunta si una "nación o el nacionalismo pueden existir desde el momento en que unos poco visionarios empiezan a soñar con ella" (Özkirimli, 2003: 346); no se puede aceptar como un movimiento circunscrito a una élite (Connor, 2004: 36), ya que, según Nairn, para el éxito de las revoluciones nacionales, las clases medias tenían que "invitar a las masas a entrar en la historia" (citado en Anderson, 1993: 120). Partiendo del siglo XVIII, el nacionalismo se fue sofisticando y expandiendo, y las naciones integraron en la "comunidad imaginada" a cada vez mayor número de ciudadanos y progresivamente a todos los segmentos de la población; esta evolución y el uso de diferentes conceptos de nación a lo largo de los siglos XIX y XX está suficientemente documentada (por ejemplo, Hobsbawm, 1992: 100152), de manera que es perfectamente plausible reconocer que naciones y nacionalismo han cobrado un sentido más completo con el paso del tiempo y, más en concreto, con la adhesión progresiva de amplias capas de la sociedad.

En definitiva, se ha podido comprobar que la modernidad implica ruptura (con la época premoderna) y novedad (una sociedad organizada por primera vez en naciones), pero los actores políticos de la modernidad, los nacionalistas, insisten en ideas radicalmente contrarias: continuidad y antigüedad. Evidentemente, para los modernistas, el énfasis de los nacionalistas en la continuidad y antigüedad de su nación es parte de la invención y construcción de la idea nacional, pero, ¿por qué tienen tanto éxito entre las masas?, ¿por qué los ciudadanos llegan a creer firmemente en la condición ancestral de sus naciones? Otros paradigmas, como el perennialismo, podrán explicarlo a partir de su rechazo a la teoría de la ruptura modernista, probando que en muchos casos las continuidades son reales y no una moderna invención.

\section{El origen de la nación desde el paradigma perennialista}

"Antes de la Segunda Guerra Mundial muchos estudiosos suscribían el punto de vista de que, aunque la ideología nacionalista fuera reciente, siempre habían existido naciones en cada período histórico, y muchas naciones existían desde tiempos inmemoriales" (Smith, 2004:67); a esta corriente se le denomina perennialismo y ha cobrado mayor vigor en los 80 y 90 (bajo la denominación, en algunos casos, de neoperennialismo), cuando ya el paradigma modernista parecía gozar de una posición hegemónica. El neoperennialismo surge precisamente frente al modernismo, desde una perspectiva defensiva ante la consolidación del grupo de teorías modernistas, para evitar que éstas se erijan en la única 
explicación aceptada sobre el origen de las naciones ${ }^{5}$. En este propósito, el nuevo perennialismo dotará de un mayor rigor científico a las propuestas teóricas del primer tercio de siglo, especialmente desde el campo de la investigación histórica (la obra de Hastings avanzada en la introducción tendrá un papel determinante).

Como ya sucedió en el apartado relativo al modernismo, y pensando que el debate que nos ocupa es el del origen, comenzaremos por las referencias estrictamente temporales de la interpretación perennialista sobre el surgimiento de las naciones y el nacionalismo. En primera instancia, el grado de consenso respecto a las fechas de nacimiento no es tan amplio como en el modernismo y quizá en lo que sí que hay acuerdo (en parte debido a ese carácter defensivo del paradigma) es en cuáles no son las fechas de aparición del fenómeno: para el perennialismo, las naciones no surgen con la modernidad, sino mucho antes; no son un fenómeno reciente, sino, como ya se ha comentado, son construcciones sociales que se remontan a tiempos más remotos. A partir de estas premisas, cada investigador situará diferentes fechas de referencia, e incluso un mismo autor (es el caso de Hastings, pero también de Grosby o Armstrong) manejará varias hipótesis, en parte apoyado en una perspectiva evolutiva, basada en la longue durée: en el camino hacia la consolidación de las características definitorias de la nación, ésta va pasando por varios estadios evolutivos que permiten identificarla en un tiempo lejano, pero que es más reconocible conforme se aproxima al presente. En otras palabras, al rupturismo modernista, el perennialismo enfrenta la continuidad histórica. Según Grosby, la afirmación de los modernistas que da por hecho la existencia de una nación estable, completamente formada y culturalmente homogénea, "está hecha al servicio de una errónea fidelidad a acusadas discontinuidades históricas” (Grosby, 2003: 9). Las ideas clave son, pues, continuidad y evolución, y de ahí cierta indeterminación en cuanto a la época de origen: no se pueden establecer fechas concretas de inicio de la nación, no es posible decir "en este momento ésta ya es una nación" porque la nación "es una obra en progreso" (Hastings, 2000: 41; citando a Eugen Weber) y el punto en que ésta deja de ser etnia ${ }^{6}$ para convertirse plenamente en una nación es de difícil determinación.

No obstante, en las obras de estos autores es posible rescatar referencias temporales (fundamentalmente en épocas premodernas) que pueden ayudar a situar el origen de la nación. En la obra crucial del paradigma, la ya citada de Hastings, se insiste en el origen medieval de las naciones. Cree reconocer las características de la nación en la Inglaterra del siglo X, en tiempos de los sajones (Hastings, 2000: 16), e incluso hay indicios de su existencia en el siglo VIII, cuando el monje Beda escribe la Historia ecclesiastica gentis Anglorum, que contiene referencias claras al pueblo "inglés" formado por sajones, anglos y jutos, que "son una nación única, con un solo idioma y una sola Iglesia" (Hastings, 2000: 56). Además, Beda habla de que ha escrito "historia nostrae nationis” y, por tanto, según Hastings, ya tenían él y otros de sus contemporáneos una idea de una comunidad concreta, con características comunes (Hastings, 2000: 57); por último, opina el autor de The construction of nationhood, políticamente también había cierta conciencia de pertenecer a una nación y de tener instituciones nacionales (Hastings, 2000: 58). Por tanto, Hastings cree encontrar pruebas de la existencia de la nación (inglesa) bastante antes del siglo X, pero, en cualquier caso, será de gran importancia dejar claro que la nación inglesa ya lo era antes de la invasión normanda (año 1066), porque el período normando supone una complicada distorsión (cambio de dinastía y élite dominante, modificaciones legales, francés como idioma cortesano ${ }^{7}$, etc.).

Reforzando esa idea de continuidad, determinante en el paradigma perennialista, al período sajón le siguen otros momentos que irán "completando" la nación inglesa y la harán cada vez más identificable (por ejemplo, la Guerra de los 100 años, 1337-1453). Tras ese momento histórico y la Guerra de los Cien Años, la reforma religiosa del siglo XVI, en parte condicionada por las necesidades que planteaba el emergente Estado-nación, va a ser el acontecimiento que en última instancia va a acabar de definir la conciencia nacional inglesa. No obstante, no estamos ante ninguna ruptura (al contrario de lo que opina Greenfeld, 2005: 326), sino sencillamente ante la culminación de un proceso histórico que tiene su inicio en el siglo $\mathrm{X}$.

5. Grosby habla de la labor que Hastings o él mismo deben llevar a cabo para "agrandar la brecha con el modernismo" (Grosby, 2003: 12), o también Llobera insiste en el carácter frentista de la obra de Hastings, que "desafía en términos convincentes la concepción modernista del nacionalismo" (Llobera, 2003: 15), pero fue el propio Hastings quien no escondió que su obra intentaba desmontar explícitamente las tesis de Hobsbawm y otros modernistas (Hastings, 2000: 12). De todos modos, Hastings reconocerá "deudas intelectuales" con Anderson, Greenfeld, Smith o Hutchinson; no así, con Hobsbawm, Gellner o Breuilly.

6. Como veremos, uno de los supuestos del perennialismo es la conexión entre etnia y nación, la continuidad entre ambos tipos de comunidad.

7. De todas maneras, ya se apresuró Hastings en subrayar que, pese a todo, no llegó a hacerse efectiva la ruptura con la nación que estaba formándose en la etapa de domino sajón, porque hay estudios que demuestran que los conquistados absorbieron a los conquistadores. La práctica desaparición del inglés escrito (sustituido por el francés) ha llevado a error a numerosos historiadores, pero lo cierto es que el inglés no dejó de hablarse y luego recuperó su lugar como lengua escrita (Hastings, 2000: 62-63). 
De cualquier forma, como el propio Hastings deja entrever y otros perennialistas se atreven a subrayar, también es posible rastrear el origen de las naciones incluso hasta la Antigüedad (Smith, 2004: 68; Yavari y Azhar, 2017). Ya Renan ("perennialista recurrente", según Smith), en su citada conferencia Qu'est-ce qu’une nation?, afirmaba que "después del final del Imperio Romano o, mejor, después de la dislocación del Imperio de Carlomagno, Europa Occidental nos aparece dividida en naciones" (Renan, 1882). Pero siguiendo con los autores más recientes, tras la muerte de Hastings en 2001, Grosby se lamentaba de que el malogrado no hubiese profundizado un poco más en su propio planteamiento, que conectaba la formación de las naciones en Europa con el ideal político bíblico -concretado en el antiguo Israel(Smith, 2003: 25), para así aceptar la existencia de naciones en la Antigüedad. Para Grosby, las propuestas teóricas de Hastings (que examinaremos más adelante) son de un valor incalculable, porque, razonablemente, permiten trasladar a la Antigüedad un mundo de naciones (Grosby, 2003: 10). También John Armstrong mantiene que antiguas etnias (judios, armenios) "registraron períodos de evidencias sobre la presencia de la nación más de un milenio atrás (...) es un patrón histórico que se debe considerar como nacionalidad perenne” (Armstrong, 2004: 12-13).

Respecto a si surgieron primero las naciones o el nacionalismo, Hastings es claro: "no voy a sugerir que el nacionalismo inglés preceda a una nacionalidad inglesa. Todo lo contrario" (Hastings, 2000: 16). Las naciones suelen configurarse antes de que aparezca la doctrina que las ensalza, al contrario de lo que opinan muchos modernistas, amparándose en aportaciones como la "invención de la tradición” (Hobsbawm \& Ranger, 1988). La crítica del historiador medievalista al modernismo es directa:

Hobsbawm escribió una historia de los nacionalismos de los siglos XIX y XX, pero no una historia del nacionalismo, y la negación de la primera mitad de la historia ha sesgado inevitablemente el conjunto. En especial, afecta a la comprensión de la relación entre nación y nacionalismo, porque mientras que en el último período los nacionalismos pueden haber precedido a menudo a las naciones en lugar de al contrario, en el primer período es mucho más acertado decir que al adquirir mayor conciencia de ellas mismas, o verse en peligro, las naciones dieron lugar a los nacionalismos (Hastings, 2000: 24)

De todos modos, la aparición postrera del nacionalismo no implica que haya que esperar hasta tiempos modernos para tener constancia de sus efectos en tanto que ideología o movimiento político como mantienen no sólo los modernistas sino también buena parte de los etnosimbolistas y quienes optan por aproximaciones evolutivas o eclécticas (ver por ejemplo Smith, 2003: 26); según Hastings, “ya había un tipo de nacionalismo inglés en el siglo XIV” (Hastings, 2000: 16), un nacionalismo de carácter defensivo que se activó durante las largas guerras con Francia.

Llegados a este punto, corresponde acometer la tarea de exponer los argumentos del perennialismo para explicar el origen de las naciones y el nacionalismo (básicamente a partir de la obra de Adrian Hastings). Tres elementos se van a combinar en las tesis de Hastings sobre el origen de las naciones: etnia, lengua vernácula y religión. En primer lugar, comparte con Smith la atención prestada a la etnia como precursora de la nación. Para él, son premisas básicas:

- la universalidad de la etnia: ese tipo de comunidad se ha dado en todas partes y en todas las épocas (Grosby, 2003: 8-9).

- la conexión entre etnia y nación: “cada etnicidad (...) tiene en su interior una nación Estado potencial (...) La conexión intrínseca entre etnicidad, nación y nacionalismo no se puede refutar. Proporciona el único punto de partida inteligible para la teoría del nacionalismo" (Hastings, 2000: 48).

La etnia entronca con la nación a partir de la lengua: las naciones emergen de las etnicidades orales. "Las lenguas orales son propias de las etnias; las lenguas vernáculas ampliamente escritas son de las naciones" (Hastings, 2000: 36); aunque no está suficientemente explicado por qué se produce el paso de la oralidad a la escritura ${ }^{8}$, Hastings mantiene que las etnias pasan a naciones cuando la lengua vernácula propia de la etnia pasa a un nivel aceptable de plasmación escrita. Es una relación directa: "cuantos más escritos con impacto popular produzca una lengua vernácula, más parece impulsar a sus hablantes desde la categoría de etnia a la de nación" (Hastings, 2000: 35). Ya vimos en el paradigma modernista que Anderson manejaba similares argumentos, aunque sin una referencia explícita a la etnia (Anderson, 1993: 70-75), no en vano, Hastings reconoce la validez del trabajo de Anderson, pero también critica su desconexión de comunidades "prenacionales", de las etnias o algún concepto análogo, además de su empeño en limitar el fenómeno nacional al período moderno. Las comunidades imaginadas de Anderson pudieron estar presentes en la mente de los pueblos mucho antes de la modernidad, a través de la transmisión de una extensa literatura oral (Hastings, 2000: 37-38).

8. Una posible explicación se centra en la necesidad de los religiosos de transmitir más efectivamente la fe, fijar los preceptos sagrados (Hastings, 2000: 37). 
Pero, en definitiva, ambos estarían de acuerdo en que el factor más determinante para la formación de las naciones es la "plasmación escrita generalizada de una lengua vernácula hablada (...) En cuanto existe una significativa lectura en lengua vernácula, crea una comunidad más consciente entre los que la leen (...) y produce rápidamente un aumento del sentimiento de particularidad histórica y cultural" (Hastings, 2000: 47-48). El hecho de que la propia lengua consiga compartir protagonismo (a través de la escritura) con las lenguas de prestigio (fundamentalmente el latín en la Europa medieval) eleva la autoestima de la comunidad de hablantes y la acerca a la toma de conciencia nacional.

La etnia también va a conectar, a través de la lengua, con la religión, porque ésta "es un elemento integral de muchas culturas, de la mayoría de las etnias y de algunos Estados. La Biblia proporcionó, para el mundo cristiano al menos, el modelo original de nación" y sin la religión no se entenderían muchas de las naciones que se han formado (Hastings, 2000: 15). Como explica Smith interpretando a Hastings:

Desde que la cristiandad adopta el Viejo Testamento (mientras rechazaba a los judios), tuvo que adoptar también su ideal político, porque el Nuevo Testamento no poseía ideales políticos propios. Como resultado de ello, el ideal bíblico de la antiguo Israel, con su fusión de territorio, población y política religiosa, que la cristiandad expandió por Europa y más allá, fue casi monolíticamente nacional. Ninguna otra tradición religiosa poseía un prototipo político similar; y ésta es la razón por la que naciones y nacionalismo son un fenómeno exclusivamente judeo-cristiano y europeo (Smith, 2003: 25)

El pretendido universalismo de la religión cristiana tuvo que pagar cierto precio particular: la territorialización de la Cristiandad, debido a que la etnicidad, como decía Hastings, también era universal, estaba en todas partes, y eso implicó que la religión tuvo que adaptarse a las diferentes etnias (Grosby, 2003: 12).

Conectando aquellos tres elementos (etnia, lengua y religión), Hastings liga estrechamente el despertar nacional a la traducción de la Biblia a las lenguas vernáculas (Llobera, 2003: 15; Hastings, 2000: 40). Smith lo sintetiza concluyendo que "las naciones y los nacionalismos fueron productos de la extensión del cristianismo en Europa, porque la cristiandad permitió el uso de lenguas vernáculas en las traducciones bíblicas y en la liturgia, y las naciones se fundamentan en las lenguas literarias" (Smith, 2003: 25). El paso del uso oral de las lenguas a su plasmación escrita fue sobre todo a través de la traducción de la Biblia (Hastings, 2000: 24), ya que en la Cristiandad medieval la religión era tema hegemónico en las publicaciones, como una de las vías para consolidar el dominio ideológico de la Iglesia (o, posteriormente, Iglesias).

\section{El origen de la nación desde el paradigma etnosimbolista y otras aproximaciones eclécticas}

El desarrollo (hasta ahora limitado) de la teoría etnosimbolista ha dado lugar a una tercera opción que se sitúa a caballo entre el modernismo y el perennialismo y que, aunque no convenza a muchos de los estudiosos, ha tenido la virtud de rescatar aspectos válidos de los otros paradigmas, dar lugar a otras aproximaciones eclécticas y romper el dominio académico del modernismo; y todo ello sin excesivas aportaciones a un debate que bebe principalmente de los desarrollos de modernistas y primordialistas/ perennialistas, así como de su enfrentamiento.

En relación a las referencias específicamente temporales al origen de la nación, los etnosimbolistas y el resto de "eclécticos", al igual que los perennialistas, se apoyan en la idea de continuidad y en una perspectiva histórica basada en la "larga duración". Smith se refiere a ello en The ethnic origins of nations: "normalmente se asume que las identidades e ideologías [nacionales/nacionalistas] son universales [primordialismo] o bastante recientes [modernismo], cuando la confrontación con los documentos históricos en un marco general normalmente demostrará las limitaciones de estas asunciones”.

En definitiva, las naciones son un fenómeno histórico que "refleja continuidad y recurrencia" (Guibernau \& Hutchinson, 2004: 2; citando un manifiesto de Smith): hay hilos conductores que enlazan a las naciones con entidades y sentimientos preexistentes, que pueden llegar a desaparecer o debilitarse para más adelante reactivarse. Pero aunque así sea, la concepción ecléctica de los planteamientos etnosimbolistas y evolutivos impide una ruptura completa con el modernismo, como sí hacen los perennialistas. Así, aunque Smith identifica "un marco preexistente de lealtades e identidades colectivas", reconoce que en la era moderna "ha habido importantes cambios en las unidades y sentimientos colectivos" (Smith, 1986: 13). Se puede buscar las raíces medievales de la nación, pero al mismo tiempo afirmar que "la nación, como una comunidad culturalmente definida, es el valor simbólico más elevado de la modernidad" (Llobera, 1996: 10). La perspectiva histórica reafirma la "continuidad", pero al mismo tiempo hay que tener en cuenta "el gran número de rupturas y discontinuidades del registro histórico” (Smith, 2004: 77). 
Por tanto, a la idea matizada de continuidad hay que añadir la de "flexibilidad temporal". El eclecticismo (o la indeterminación, si se quiere) impide en muchos casos la concreción de fechas o épocas concretas, al margen de plantear la posibilidad de que existan naciones premodernas. De todos modos, como en el perennialismo (o como consecuencia de sus postulados), son frecuentes las referencias a la Antigüedad y a la Edad Media. En este sentido, y como ya vimos en Steven Grosby, Smith considera que, dando por buenos los argumentos de Hastings, "seguramente se podrían encontrar naciones en la Antigüedad" (Smith, 2003: 26) y también Armstrong (a medio camino entre el perennialismo y el etnosimbolismo) encuentra evidencias de la presencia de naciones en esa época (Armstrong, 2004: 12-13).

Pero más frecuentes y sólidas son las referencias a la Edad Media: lo que se debe intentar captar "es el proceso y los elementos constitutivos de la formación de la conciencia en la Edad Media. Es importante constatar que al final de la época medieval la suerte etnonacional estaba echada" (Llobera, 1996: 13), porque en esa época diferentes elementos (culturales y políticos) cristalizaron en lo que se puede llamar una "nación" a través de la huella que dejaron en la "mentalidad colectiva de los diferentes pueblos" (Llobera, 1996: 19). Llobera reitera contundentemente su apuesta por el período medieval incluso cuando deja traslucir su eclecticismo: "decir (...) que la nación y el nacionalismo como los entendemos hoy día no existían en la Edad Media es una perogrullada. Abandonar, por esta razón, cualquier investigación sobre el proceso de formación nacional y sobre las formas de identidad nacional en este período sólo puede conducirnos a un desastre sociológico" (Llobera, 1996: 19).

Pero, si bien evolucionistas y etnosimbolistas creen adecuada la búsqueda de los orígenes de la nación en la Edad Media (o incluso en la Antigüedad), en lo concerniente al nacionalismo (la ideología, el movimiento político) se resisten a rechazar las tesis modernistas, que sitúan su aparición a finales del siglo XVIII (así se expresa en Llobera, 1996: 9 y 14; y Smith, 2003: 27), aunque algún autor mantenga el paralelismo cronológico entre nación y nacionalismo, y, por consiguiente, la posibilidad de que el nacionalismo también tenga su origen en una época premoderna.

Para Smith, el intento de situar el nacionalismo en una época premoderna "surge de la confusión entre 'sentimiento nacionalista' y 'nacionalismo', entre el sentimiento de pertenecer a una nación y el programa político para su autonomía, unidad e identidad" (Smith, 2003: 26) ${ }^{9}$. No es aceptable, por tanto, el concepto de "nacionalismo defensivo" que emplea Hastings, porque no lleva aparejado un programa político sino la activación bajo amenaza de ese sentimiento.

De esto último se desprende que, para los autores eclécticos, la nación precede habitualmente al nacionalismo. En este sentido, se encuentran incómodos ante la idea de "invención” o "fabricación” de la nación que manejan buena parte de los modernistas. En todo caso, los nacionalistas se nutren de las etnias y sus recursos culturales para dar forma a la nación, que será herencia de elementos y entidades preexistentes (Routledge, 2003: 225). El nacionalismo no moviliza a las masas desde la nada o desde tradiciones completamente inventadas, aunque posteriormente redefina algunos de los símbolos y mitos que utiliza para reforzar su representación ante los miembros de la nación, en lo que se podría denominar una estrategia de "marketing nacional". En esta línea, la "reapropiación” representa una "incursión en el pasado étnico para obtener los materiales auténticos y el carácter distintivo de una nación moderna” (Smith, 1999b: 12).

Al margen de la perspectiva a largo plazo, el etnosimbolismo (y en parte también otras corrientes eclécticas) se basa, fundamentalmente, en los siguientes preceptos:

- “Alejarse del análisis exclusivamente orientado a las élites, característico del modernismo” (Smith, 2004: 76).

- "El análisis de la aparición de las naciones y el nacionalismo se sitúa en un marco de identidades culturales colectivas anteriores, especialmente de comunidades étnicas o etnias" (Smith, 2004: 77).

- "Los componentes preexistentes y las continuidades de larga duración de las comunidades étnicas y las naciones son culturales y simbólicos" (Guibernau \& Hutchinson, 2004: 1).

A pesar del énfasis en elementos subjetivos, y en la continuidad histórica comunidades étnicas-comunidades nacionales, conviene insistir en que estos autores no abandonan muchos de los preceptos modernistas, como por ejemplo la decisiva influencia de la aparición hegemónica del modo de producción capitalista o el papel determinante del Estado y sus mecanismos de inclusión en la formación de las naciones y el auge del nacionalismo (Smith, 2003: 27; Llobera, 1996 : 14 y

9. Con anterioridad, Smith aceptaba, como Hastings o Guibernau, la existencia de los dos tipos de nacionalismos: "el nacionalismo es un movimiento ideológico moderno, pero también la expresión de las aspiraciones de varios grupos sociales para crear, defender o mantener naciones (...) recurriendo a los recursos culturales de comunidades y categorías étnicas preexistentes” (Smith, 1999b: 18). 
133-197); Guibernau, 1996: 57-76). Entienden que la influencia de estos factores ya ha sido suficientemente trabajada desde el modernismo (y en muchos casos de manera satisfactoria) y los etnosimbolistas tienen que ahondar en aspectos todavía poco claros de la teoría social sobre naciones y nacionalismo, especialmente la complejidad de sus componentes subjetivos.

\section{Limitaciones del modernismo y puntos de encuentro con el paradigma perennialista}

Las limitaciones a las que se va a hacer referencia tendrán que ver especialmente con el principal argumento del modernismo, es decir, que las naciones y el nacionalismo son un producto de la modernidad. De esta manera, se han rastreado planteamientos poco sólidos y algunas concesiones o asunciones de la presencia en épocas premodernas de elementos que conectan directamente con la nación moderna, o que pueden ser incluso un avance de la nación en tiempos anteriores a la modernidad.

Respecto a las referencias específicamente temporales, elemento de necesaria recurrencia en todo el análisis comparado de paradigmas, sorprende que, por ejemplo, Anderson adivine ya en algunos relatos de Marco Polo, del siglo XIII, "la semilla de una territorialización de las creencias que anuncia el lenguaje de muchos nacionalistas" (Anderson, 1993: 36). Se trata de un retroceso de, aproximadamente, medio milenio respecto a la fecha de referencia del modernismo (concretamente 1789 o, en general, finales del siglo XVIII-principios del siglo XIX) y abre la posibilidad de la existencia de sentimientos nacionalistas o cierto grado de conciencia sobre la propia nación y otras en plena Edad Media.

Este tipo de concesiones a enfoques que priman la perspectiva histórica o se aproximan al fenómeno teniendo en cuenta las posibles continuidades históricas no son una excepción; por ejemplo, Gellner planteó (sin excesivo desarrollo) un modelo explicativo más ecléctico en su obra póstuma que en la que expuso en los años sesenta. También Connor se aproximaba a la idea de continuidad en When is a nation? al comentar que:

El retraso (...) entre la aparición de la conciencia nacional entre segmentos de la elite y su extensión a las masas nos recuerda el obvio pero frecuentemente ignorado hecho de que la formación de la nación es un proceso, no un suceso o un evento (...) Los eventos son fechados con facilidad, no así las fases de un proceso (Connor, 1990)

Pero las excepciones o posibles concesiones de los modernistas suelen partir del siglo XVI, sobre todo a raíz de la obra de Liah Greenfeld (Nationalism: five roads to modernity, Harvard University Press, Cambridge, Massachusetts, EEUUA, 1992) que situó la Inglaterra de los siglos XVI-XVII como el tiempo y el espacio de nacimiento de la nación, porque es en ese lugar y ese momento donde Greenfeld cree ver el inicio de la modernidad, fundamentalmente debido a que tomó cuerpo el Estado moderno y la conciencia secular (moderna en definitiva) sustituyó a la religiosa. Asimismo, nuevamente Benedict Anderson deja entrever que esta época tiene relativa importancia en la formación de las naciones y, más en concreto, en su argumento de la vernacularización de las lenguas escritas y la revolución que supuso la imprenta, ya difundida a toda Europa en este siglo. Por ejemplo, según Anderson, las lenguas vernáculas ya tenían una presencia muy mayoritaria en la Administración en esta época (Anderson, 1993: 68); o el francés impreso superaba con creces al latín impreso en Francia en la segunda mitad del siglo XVI (Anderson, 1993: 38). Si, en su análisis, Anderson le diese a las continuidades históricas la misma importancia que le dan los autores evolucionistas o que basan sus investigaciones en la longue durée, no podría afirmar tan taxativamente que naciones y nacionalismo aparecen a finales del siglo XVIII.

Tilly también apunta que durante las reformas protestantes del siglo XVI coincidieron en muchos casos reivindicaciones religiosas y políticas; es el caso de Holanda, pero también de Inglaterra o Escandinavia. Este siglo es decisivo porque, tras ese periodo de revueltas contra el poder de la Iglesia católica, "la lengua común, la tierra y el mito sobre los orígenes adquirieron preeminencia sobre la religión como base de las reivindicaciones revolucionarias” (Tilly, 1995: 71). También Craig Calhoun se permite alguna concesión cuando afirma que "el discurso nacionalista se ha desarrollado en los últimos 300 años aproximadamente" (Calhoun, 1994: 320). Finales del siglo XVII-principios del siglo XVIII, es cuando Locke pública su pensamiento filosófico-político del que partirá el liberalismo político, de vital importancia para lo que muchos han denominado el nacionalismo cívico.

Como ya se ha avanzado, para matizar y completar su planteamiento teórico, Gellner es de los autores modernistas que en mayor medida recogió otros enfoques que abren la puerta a las continuidades históricas (quizá influido por su estrecho contacto con Anthony D. Smtih). Así, admite que en las sociedades agrarias preindustriales ya se planteó el problema de la legitimidad de la unidad política, existían Estados y los nacionalistas no estaban ausentes, aunque fuesen minoritarios (Gellner, 1998: 26). "Determinados rasgos sociales que se pueden encontrar en el mundo agrario (...) pueden 
llevar al tipo de homogeneización cultural que demanda el nacionalismo" (Gellner, 1998: 33). Y reconoce que tras el Congreso de Viena (1815), las primeras rebeliones nacionalistas (Grecia y los Balcanes) frente al orden imperial de los Habsburgo, Romanov y otomanos, se dan en países no industrializados (Gellner, 1998: 48-49), con lo cual la asociación del nacionalismo a la modernidad queda en entredicho. En definitiva, industrialización y democratización, procesos que acompañan y posibilitan la formación de la nación moderna para muchos autores de esta corriente, no se han dado de manera uniforme (de hecho, hay países que todavía no los han experimentado) y aún así se ha llegado a un mundo de naciones. Por tanto, pueden ser elementos fundamentales para la configuración inicial de determinado tipo de naciones y nacionalismo, pero quizá no expliquen la extensión del fenómeno hasta nuestros días.

También conviene detenerse en el controvertido concepto de “protonación”, empleado por Hobsbawm inicialmente para establecer una nítida barrera respecto a la nación:

En muchas partes del mundo los estados y los movimientos nacionales podían movilizar ciertas variantes de sentimientos de pertenencia colectiva que ya existían y que podían funcionar, por así decirlo, potencialmente en la escala macropolítica capaz de armonizar con estados y naciones modernos. A estos lazos los llamaré 'protonacionales' (...):

- formas supralocales de identificación popular que van más allá de las que circunscriben los espacios reales en que las personas pasaban la mayor parte de su vida (...)

- o lazos y vocabularios políticos de grupos selectos vinculados de forma más directa a estados e instituciones y que pueden acabar generalizándose, extendiéndose y popularizándose

Ésos últimos tienen más en común con la nación moderna. No obstante, ninguno puede identificarse legítimamente con el nacionalismo moderno que pasa por ser su extensión lineal, toda vez que no tenían o no tienen ninguna relación necesaria con la unidad de organización política territorial que constituye un criterio crucial de lo que hoy en día entendemos como 'nación' (Hobsbawm, 1992: 55-56).

Asume la existencia de estos antecedentes, de la presencia de elementos "protonacionales" (lengua, costumbres, símbolos) que hacían vislumbrar a nivel popular la aparición de las naciones, pero se apresura a desligarlos de la nación moderna. Continúa afirmando que el más decisivo criterio de protonacionalismo es "la conciencia de pertenecer o haber pertenecido a una entidad política duradera" (Hobsbawm, 1992: 81); y vuelve a sugerir la conexión con la nación moderna cuando mantiene que:

...de una forma u otra la pertenencia a un estado histórico (o real), del presente o del pasado, puede actuar directamente sobre la conciencia del pueblo llano y producir protonacionalismo, o, tal vez, como en el caso de la Inglaterra de los Tudor, incluso algo próximo al patriotismo moderno" (Hobsbawm, 1992: 84)

...el protonacionalismo, allí donde existía, facilitaba la tarea del nacionalismo, por grandes que fuesen las diferencias entre los dos, por cuanto los símbolos y sentimientos existentes de comunidad protonacional podían movilizarse detrás de una causa moderna o un estado también moderno (Hobsbawm, 1992: 86)

Por tanto, vuelve a remontarse al siglo XVI y no descarta la conexión, la continuidad, entre épocas premodernas y la modernidad, aunque sea a través del artificio "protonación", al que niega cualquier parecido a la "etnia", ya que, aunque ésta pudiese tener su importancia, el hecho de que muchos Estados o naciones sean multiétnicos complica la presentación de la etnia como un antecedente válido para todas las naciones (Hobsbawm, 1992: 72-73). En último término, parece que intuye la posibilidad de que exista algún grado de conciencia nacional en épocas premodernas (nunca más atrás del siglo XVI en cualquier caso), pero el obstáculo para asumirlo de pleno es la imposibilidad de saber qué pasaba por la mente de las masas en esas fases previas (Hobsbawm, 1992: 86). En conclusión, a partir de citas como las que se han repasado (pese a todos los matices que las acompañan), se hace un tanto difícil entender una postura que defiende una marcada frontera entre la modernidad y el período anterior.

En suma, prácticamente todos los modernistas son capaces de observar rasgos de la nación moderna en épocas precedentes y, más claramente, detectan antecedentes de la nación moderna a partir del siglo XVI (cuando no antes), mostrando, pese a su énfasis en el cambio, en la ruptura, que existen continuidades históricas entre elementos previos (etnia, protonación, formas de identificación popular, conciencia nacional, sentimiento nacionalista, etc.) y naciones y nacionalismo modernos. Partiendo de una perspectiva histórica que tome en consideración la larga duración y el hecho de que este tipo de fenómenos (identidades colectivas y sus representaciones) son procesos, es prácticamente ineludible observar continuidades entre lo que definimos como moderno y formas previas, que podríamos denominar "en transición”. Del mismo modo que la modernidad y sus vertientes material y política ("desarrollo ilimitado de las fuerzas 
productivas" y "principio de igualdad entre los hombres") tienen sus antecedentes principalmente en la Inglaterra y los Paises Bajos del siglo XVI y XVII (desarrollo del capital mercantil previo al capital industrial, primeras experiencias de democratización limitada, etc.), es razonable pensar que también la nación (seguramente a partir de los modelos inglés y holandés) tiene sus orígenes, aunque sea a través de modelos no completos, en épocas premodernas.

En otro orden de cosas, si en algún momento comentábamos que la profundización en los argumentos perennialistas podía trasladar el origen de las naciones de la Edad Media a la Antigüedad, determinados planteamientos modernistas pueden llevarnos a épocas más recientes (finales del siglo XIX o incluso el siglo XX). Siguiendo esta idea, se podría plantear un recorrido cronológico desde 1830 (tímido inicio de aplicación del "principio de nacionalidad") hasta la segunda mitad del siglo XX (aplicación del “derecho de autodeterminación” y extensión de los medios de comunicación de masas) en base a las reservas que plantean los principales autores modernistas sobre si el sentido completo de la nación se daría en torno a la fecha de referencia o en una etapa posterior. Si la nación es una obra en construcción, las evidencias que aportan los propios modernistas dejan claro que los "acabados" de la edificación se prolongaron hasta el siglo XX y, por tanto, no sería descabellado sostener que la nación tal como la concebimos en la actualidad (la nación moderna) tuvo su origen en este siglo, tras más de 100 años de transición. Más en concreto, si la aparición de los medios de comunicación de masas (primero la imprenta/prensa y luego sucesivamente los otros) fueron clave para la difusión de la idea de nación (lo afirma claramente Anderson, Gellner en cierta manera, y también Hobsbawm, que llega incluso al momento en que la radio -nacional- posibilita una difusión mayor de la idea de nación), y se entienden la nación y el nacionalismo como fenómenos de masas, quizá no podríamos hablar de ellos realmente hasta que esos medios de comunicación fueron realmente de masas y eso nos llevaría hasta un avanzado siglo XX. En definitiva, una perspectiva evolutiva, que prime la idea de continuidad, se remontaría más atrás de 1789 y sostendría que la nación se ha ido conformando hasta alcanzar su versión más avanzada en la segunda mitad del siglo XX, quizá cuando la escala nacional empezaba a perder su sentido para un capital ya verdaderamente transnacional.

\section{Limitaciones del perennialismo y puntos de encuentro con el paradigma modernista}

En la línea de lo que se ha desarrollado en el apartado anterior, en éste se va a profundizar en argumentos utilizados por autores perennialistas que les acercan a las posiciones del modernismo o que, al menos, suponen una aceptación de ciertos razonamientos o no implican un rechazo rotundo a las tesis modernistas. Se comprobará que el perennialismo admite en cierta manera el papel intensificador del mundo moderno, sin perder de vista que naciones y nacionalismo tienen una raíz que va más allá de la época moderna.

En primer lugar, conviene resaltar que, pese al énfasis otorgado por el perennialismo a la idea de continuidad, también se adivina, como sucede con el modernismo, cierto empeño en fechar el origen de la nación, en afirmar que en determinado momento o gracias a tal acontecimiento ya podemos hablar de naciones. Esta particularidad sitúa al perennialismo entre la ruptura y la continuidad, como se vio que también sucedía en el modernismo, y conduce a una lectura de ambos paradigmas desde una perspectiva integradora.

Pero no únicamente se asumen cambios profundos en el período antiguo o la Edad Media que pueden ser responsables de la aparición de determinadas naciones. Hastings asumirá en algunas ocasiones que a partir de la época moderna se produjo una intensificación del fenómeno, no desea "cuestionar la rápida extensión de la ideología nacionalista y de los movimientos de creación de naciones en esa época” (Hastings, 2000: 23). Aunque hay que situar el origen de la nación en la sociedad medieval, el resultado final es "otra gran realidad de la experiencia occidental moderna" (Hastings, 2000: 24). Si, como ya se avanzó, Hastings considera el nacionalismo una “obra en construcción”, fruto del análisis a partir de una perspectiva histórica, su aceptación de la intensificación del fenómeno en la época moderna, supone asumir que es el momento en el que se culmina la "obra". Fechar el origen de naciones y nacionalismo en la Edad Media (o en cualquier otra época), por el contrario, contradice el empleo de tal perspectiva. El mérito de Hastings es aportar al estudio de la nación evidencias de las raíces medievales del fenómeno, pero si asumimos parte de sus preceptos (básicamente, la idea de continuidad), no es aceptable marcar puntos fijos de partida, sino considerar cualquier momento clave como un peldaño en la evolución de la nación.

Como observa Smith, "Hastings admite que la teoría del nacionalismo fue moderna, pero declara que la teoría no es muy importante” (Smith, 2003: 26). En el inicio de The construction of nationhood, Hastings sostenía que

El término nacionalismo tiene dos componentes: uno teórico y otro práctico. Como teoría política (la de que cada 'nación' debería disponer de su propio 'Estado') deriva del s. XIX (Hastings, 2000: 14) 
Seguidamente, expone el componente "práctico", el ya revisado concepto de "nacionalismo defensivo", al que otorga una importancia mayor que a la doctrina, programa o ideología nacionalista, asumida como moderna. En la misma línea, admite que la era de los nacionalismos a que se refieren los modernistas es "una especie de nacionalismo de nivel II", un segundo grado en que cobra protagonismo el programa nacionalista y los proyectos de construcción de la nación. Nuevamente, la apuesta por una perspectiva evolutiva no restaría importancia a esta segunda fase, que completaría el sentido moderno de la nación. Otra cuestión es que se quiera admitir la modernidad del concepto y ése no es el caso de Hastings.

Aún así, la importancia que Hastings concede a la modernidad y su relación con naciones y nacionalismo va más allá de la anécdota. Por ejemplo, para subrayar la adecuación del modelo inglés como espacio de origen de la nación, afirma que

¡Sólo si la identidad nacional y el nacionalismo fueran fenómenos marginales dentro la modernización del mundo durante los últimos tres siglos resultaría fácil imaginar que no afectaran al país que durante todo este tiempo, hasta el momento de su declive, lideró la modernización! De hecho, son elementos centrales e indispensables de ese movimiento y sin ellos sería difícil imaginar la evolución del mundo moderno (Hastings, 2000: 18)

Precisamente, sostiene que el surgimiento inicial de la nación inglesa la preparó para liderar la modernidad (un liderazgo que ya desempeñó como Gran Bretaña, forjando su extenso imperio), aportando diferentes evidencias de la vinculación de Inglaterra con la emergencia del mundo moderno, especialmente en lo relativo al papel del Estado y el capital (Hastings, 2000: 17-18). La fase preparatoria, el momento en que se consolida la nación inglesa, es el siglo XVI, cuando algunos acontecimiento de carácter bélico impulsan el espíritu nacional y triunfa la Reforma.

Sea en la época moderna o en el siglo XVI, lo cierto es que Hastings admite en numerosas ocasiones que la nación inglesa se "completa" en un período posterior a la Edad Media ${ }^{10}$. Y, en este sentido, la modernidad es una segunda fase en que, además, reconoce que "los nacionalistas pueden haber precedido a las naciones en lugar de al contrario" (Hastings, 2000: 24).

\section{Balance final. La hipótesis de la continuidad-intensificación.}

En general, este recorrido por las posiciones de los principales paradigmas en relación al origen de naciones y nacionalismo, ha tenido por objetivo la localización de los puntos de encuentro entre las diferentes aproximaciones, fundamentalmente porque los autores de los diferentes paradigmas ya se afanan en remarcar la diferencia. En cualquier caso, no se trata de esconder las importantes diferencias entre unos y otros y, en este sentido, los tres primeros apartados han querido indicar los aspectos en los que cada paradigma pone el acento. Así, hemos comprobado el énfasis que el modernismo pone en la aplicación del principio de racionalidad en sus vertientes material y política, y cómo los procesos de índole económica (revolución industrial, asentamiento del modo de producción capitalista) y política (democratización) han jugado un papel clave para la consolidación de una cultura moderna, que es, en definitiva, una cultura nacional. También se ha prestado atención a la interrelación entre etnia, religión y lengua, que permitía a los perennialistas situar el origen de la nación en tiempos premodernos. Y, en tercer lugar, el etnosimbolismo y otros acercamientos eclécticos se confirman como una tercera vía que no rechaza la aparición de naciones premodernas, al fijar estrechos (aunque difusos) vínculos entre etnia y nación (subrayando la importancia de lazos emocionales, símbolos y mitos, que garantizan una continuidad), pero sin restar importancia a la modernidad como fase postrera en que el movimiento y la ideología nacionalista juegan un papel fundamental de definición y reelaboración de aquellos elementos de continuidad.

Pero en los siguientes apartados ya hemos reconocido algunos de los argumentos de las posiciones eclécticas tanto en modernistas como en perennialistas y ello nos ha facilitado elementos para plantear la propuesta final. En primer lugar, es necesario entender la nación como un fenómeno socialmente construido y sobre este particular apenas hay discrepancia (salvo en el caso de la mayoría de las corrientes primordialistas). Dando por hecho que las naciones son "obras en construcción", parece lógico adoptar una perspectiva histórica que tenga en cuenta la larga duración, que prevea el seguimiento de las continuidades históricas más allá de la época moderna. Llevada esta óptica hasta sus últimas consecuencias, parece absurdo fechar la aparición de las naciones, ya que, si sólo buscamos indicios podremos remontarnos incluso a la Antigüedad, mientras que si nuestro objetivo es localizar la "nación acabada" seguramente debamos trasladarnos al siglo XX, posiblemente al final de la primera mitad.

10. En otro ejemplo, aunque Hastings insiste en las raíces medievales de la nación francesa, acepta que necesitó la Revolución "para hacerse plenamente consciente" (Hastings, 2000: 42). 
La nación es una realidad con raíces históricas premodernas, que pueden incluso localizarse, si se quiere, en la Antigüedad, pero que son más reconocibles a partir de la Edad Media (recordemos: "al final de la época medieval la suerte etnonacional estaba echada"; Llobera, 1996: 13). A partir del siglo XVI, cuando están conformándose los elementos constitutivos de la modernidad, cuando transcurre la "prehistoria" del mundo moderno (capital mercantil, reformas políticas, ruptura del monopolio ideológico de la Iglesia católica), empieza a forjarse la nación tal como la entendemos en la actualidad, la nación moderna. Por último, a partir de finales del siglo XVIII se inicia la fase de intensificación del fenómeno nacional, con un protagonismo inequívoco del movimiento e ideología nacionalistas, que dará lugar a programas más o menos precisos de construcción nacional. A través de determinados hitos, el "principio de nacionalidad” se va a extender progresivamente a todo el sistema mundial, al tiempo que se articulan mecanismos de participación y los miembros de la nación tienen acceso a los medios de comunicación y por tanto a una cultura (nacional) de masas.

Este resumen, que plantea una postura ecléctica a partir de la revisión de las posiciones de la teoría social sobre la nación y, en concreto, sobre su origen, supone enunciar lo que se ha querido denominar la hipótesis de la continuidadintensificación $n^{11}$, una propuesta en absoluto innovadora, puesto que en cierta manera es una categorización sintética de la que mantienen estudiosos como Josep R. Llobera y algunos de los autores eclécticos que han aparecido en este texto, sin que por ello se ajuste a lo que Smith presenta como etnosimbolismo, cuyos presupuestos teóricos él mismo reconoce en fase de desarrollo. De hecho, el camino de la etnia a la nación está todavía por completar, a pesar de que hay importantes avances (por ejemplo, es de gran utilidad la distinción entre una etnicidad básicamente oral y una nación que puede "imaginarse" o mostrarse a través de la escritura).

La adopción de esta perspectiva, que incluso autores inicialmente modernistas como Kerr (2021) parecen adoptar, permite la aproximación al fenómeno sin tener en la variable tiempo un obstáculo y posibilita centrar la atención en las características de los diferentes movimientos nacionales y en la identificación de los elementos que dan sentido a la nación (o más en concreto, a las naciones a las que se quiera someter a estudio). En esa nueva tarea, será fundamental tener claro el concepto de nación del que se parte, que es otro terreno de dilatada disputa.

\section{Bibliografía}

Anderson, B. (1993). Comunidades imaginadas. Reflexiones sobre el origen y la difusión del nacionalismo. México D.F.: Fondo de Cultura Económica.

Armstrong, J. (2004). “Definitions, periodization, and prospects for the longue durée”, Nations and Nationalism, 10 (1/2), 9-18. https://doi.org/10.1111/j.1354-5078.2004.00151.x.

Arnau, J. A. y M. Nieto (2002). “Democracia y sociedad moderna”, Laberinto, 9.

Billig, M. (1995). Banal nationalism. Londres: Sage.

Breuilly, J. (1990). Nacionalismo y Estado. Barcelona: Pomares-Corredor.

Calhoun, C. [editor] (1994). Social theory and the politics of identity. Cambridge: Blackwell.

Connor, W. (2004). “The timelessness of nations”, Nations and Nationalism, 10 (1/2), 35-47. https://doi.org/10.1111/j.13545078.2004.00153.x.

Connor, W. (1990). “When is a nation?”, Ethnic and Racial Studies, 13, 92-103. https://doi.org/10.1080/01419870.1990.9993663.

Gellner, E. (1998). Nacionalisme. Catarroja: Afers-Universitat de València.

Greenfeld, L. (2005). "Nationalism and the mind", Nations and Nationalism, 11 (3), 325-341. https://doi.org/10.1111/j.13545078.2005.00207.x.

11. En el fenómeno nacional existen continuidades históricas que sugieren buscar las raíces de la nación en épocas premodernas, pero la modernidad, la aplicación del principio de racionalidad, supone una importante transformación de las colectividades etnonacionales, de tal modo que se produce una intensificación del fenómeno y una extensión a todo el sistema mundial. 
Grosby, S. (2003). "Religion, ethnicity and nationalism: the uncertain perennialism of Adrian Hastings", Nations and Nationalism, 9 (1), 7-13. https://doi.org/10.1111/1469-8219.00070.

Guibernau, M. (1996). Los nacionalismes. Barcelona: Ariel.

Guibernau, M. y J. Hutchinson (2004). "History and national destiny”, Nations and Nationalism, 10 (1/2), 1-8. https://doi. org/10.1111/j.1354-5078.2004.00150.x.

Hastings, A. (2000). La construcción de las nacionalidades. Etnicidad, religión y nacionalismo. Madrid: Cambridge University Press.

Hobsbawm, E. J. (1992). Naciones y nacionalismo desde 1780. Barcelona: Crítica. https://doi.org/10.1017/CCOL0521439612.

Hobsbawm, E. J. y T. Ranger [compiladores] (1988). L'invent de la tradició. Vic: Eumo.

Kerr, William (2021). Darwinian Social Evolution and Social Change. The Evolution of Nationalisms. Londres: Palgrave-Macmillan https://doi.org/10.1007/978-3-030-77999-3.

Llobera, J. R. (2003). “A comment on Hastings's The Construction of Nationhood”, Nations and Nationalism, 9 (1), 15-17. https://doi.org/10.1111/1469-8219.00071.

Llobera, J. R. (1996). El dios de la modernidad. El desarrollo del nacionalismo en Europa Occidental. Barcelona: Anagrama.

Özkirimli, U. (2003). “The nation as an artichoke? A critique of ethnosymbolist interpretations of nationalism”, Nations and Nationalism, 9 (3), 339-355. https://doi.org/10.1111/1469-8219.00100.

Renan, E. (1882). Qu'est-ce qu'une nation?, conferencia leída en la Sorbona el 11 de marzo. Disponible en http://www.bmlisieux. com/archives/nation01.htm (visita el 23-5-2021).

Routledge, B. (2003). “The antiquity of the nation? Critical reflections from the ancient Near East”, Nations and Nationalism, 9 (2), 213-233. https://doi.org/10.1111/1469-8219.00083.

Smith, A. D. (2004). Nacionalismo. Madrid: Alianza Editorial.

Smith, A. D. (2003). "Adrian Hastings on nations and nationalism", Nations and Nationalism, 9 (1), 25-28. https://doi. org/10.1111/1469-8219.00073.

Smith, A. D. (1999a). "Ethnic election and national destiny: some religious origins of nationalist ideals", Nations and Nationalism, 5 (3), 331-355. https://doi.org/10.1111/j.1354-5078.1999.00331.x.

Smith, Anthony D. (1999b). Myths and memories of the nation. Oxford: Oxford University Press.

Smith, A. D. (1995). "Nations and their pasts", The Warwick Debates on Nationalism, Warwick University.

Smith, A. D. (1986). The ethnic origins of nations. Oxford: Basil Blackwell.

Thiesse, A.-M. (1999). "Democracy softens forces of change: inventing national identity", Le Monde Diplomatique, junio.

Tilly, C. (1995). Las revoluciones europeas, 1492-1992. Barcelona: Crítica.

VV.AA. (1996). La questió nacional: un debat obert. Barcelona: Fundació Pere Ardiaca.

Woods, A. y T. Grant (2000). Marxism and the national question, en http://www.marxist.com/Theory/national question. html (visita el 23-5-2021).

Yavari, A. y Z. Azhar (2017). The Origins of Nation and Subjecthood in Ancient Rome: from Gens to Subjecthood, from Citizenship to Nation. Comparative Law Review, 8 (1), 55-. 